\title{
Memorias de la guerra Contrainsurgente \\ EN GUATEMALA: HACIA UNA RUPTURA DE LA \\ VICTIMIZACIÓN
}

\section{Memories of the Guatemala Civil War: Breaking the Posture of the Victim}

\begin{abstract}
Anelí Villa Avendaño ${ }^{1}$
Resumen: El presente artículo hace una revisión historiográfica de trabajos paradigmáticos relacionados con la memoria histórica de la guerra contrainsurgente en Guatemala (1954-1996), centrada en cuatro ejes principales. El primero son las causas que ocasionaron la guerra. El segundo los actores que la protagonizaron, debatiendo entre la teoría de los dos demonios y una reconstrucción compleja de los sujetos. El tercer eje se centra en el tema de si el perdón y la reconciliación deben ser percibidos como los objetivos de la recuperación de la memoria histórica. Y finalmente planteo una discusión acerca de la participación activa o pasiva de los pueblos indígenas en las reconstrucciones locales de la memoria. Este es el punto medular del artículo, pues la mayoría de las narrativas siguen construyéndose sobre la victimización, reduciendo o negando el papel activo de la población. Con esta crítica planteo las pistas para salir de ella a través del reconocimiento de todos los actores como sujetos políticos con capacidad transformadora.

Palabras clave: memoria histórica, guerra contrainsurgente, Guatemala, rebelión política, victimización, justicia transicional, derechos humanos.

\footnotetext{
${ }^{1}$ Maestra en estudios latinoamericanos, doctorante en estudios latinoamericanos de la UNAM. Líneas de investigación: memoria histórica, teología de la liberación, guerra en Guatemala. Correo electrónico: lavidaesunviajeenparacaidas@hotmail.com. Fecha de recepción: 1211 16; Fecha de aceptación: 200316.
}

(cc) BY-NC-ND Páginas 19-48. 
Abstract: This research is an histographical review of paradigmatical works/papers in Historical Memory of the Guatemala civil war focused in four main axes. The first its about the causes that produced the conflict. The second on the way how the involved actors are represented, in other words, if it's assumed that there were only two parts in the conflict or otherwise the entire society will be taken as a participant of the process. The third axis is centered on the issue of whether the forgiveness and reconciliation must be perceived as the objective of the Recovery Historical Memory. At last, I will argue about the active or passive participation of the indigenous people in local reconstructions of memory. This is the critique medullar point, because the majority of the narratives have been constructed from the posture of victimization that reduces the active role of the civil population. With this review I raise the clues to get out of the victimization through recognition of all actors as political subjects with transformative capacity.

Keywords: historical memory, Guatemala, civil war, political rebellion, victimhood, transitional justice, human rights.

\section{La memoria histórica en el contexto guatemalteco}

El presente artículo busca ser una contribución crítica a los procesos de reconstrucción de la memoria histórica de la guerra contrainsurgente en Guatemala, ${ }^{2}$ para ello se hará una revisión historiográfica de diversos trabajos que se han elaborado, desde las historias oficiales hasta procesos de rescate de memorias locales, memorias de las mujeres y, finalmente, las de los familiares de detenidos o asesinados en tiempos de la guerra. Me he valido para ello de una amplia recopilación bibliográfica

\footnotetext{
${ }^{2}$ El término más utilizado para referirse a este periodo de la historia es el de conflicto armado interno, sin embargo coincido con Edelberto Torres Rivas en que este nombre no se ajusta a los hechos ocurridos en Guatemala, pues la violencia del ejército contra las poblaciones fue atroz y desproporcionada con respecto a las movilizaciones sociales y al número real de guerrilla existente en el país (Torres, 2007). Se nombra aquí guerra contrainsurgente pues bajo el objetivo de eliminar cualquier forma de insurgencia el ejército desató una guerra ofensiva contra poblaciones combatientes y no combatientes, sin que en la mayoría de los casos hubiera confrontación de la otra parte.
} 
en la que se encuentran los trabajos principales del periodo en cuestión (1954-1996), así como del acompañamiento directo a algunos grupos que trabajan en la materia, con lo anterior he podido constatar la visión de la historia que se tiene y la forma de como se aborda. De esta investigación se desprende el eje central del artículo que consiste en afirmar que la gran mayoría de relatos de la guerra se han narrado basados en la figura de la víctima, ${ }^{3}$ y que es preciso ser críticos de esta imagen para poder así promover el reconocimiento de los sujetos políticos con capacidad de transformación.

La memoria histórica no es el recuerdo simple de lo vivido, pasa por una interacción con lo social que nos lleva a poner esos recuerdos en colectivo y a estructurar un relato ordenado sobre lo que nos ha pasado. Se parte de la experiencia personal pero se logra vislumbrar su dimensión histórica, entender que los hechos que nos atravesaron la vida y el cuerpo no son accidentes aislados, daños colaterales ni producto del azar, sino que forman parte de un complejo entramado. Cuando se ha vivido una guerra tan atroz como la que tuvo lugar en Guatemala entre 1954 y 1996, recuperar la memoria histórica se vuelve fundamental para lograr entender el porqué de las cosas y con ello plantear las acciones que se necesitan emprender para evitar que se repita el horror. No basta para sanar a una sociedad de posguerra con que se firme la paz y se decrete la reconciliación como ley, es necesario abrir los ojos para mirar lo que ocurrió, escudrińar en los profundos conflictos sociales con el fin de entender su vigencia y generar transformaciones que de fondo logren evitar que la violencia domine el escenario social.

Es preciso anotar que el recuperar la memoria histórica no se trata solo de narrar el pasado, pues a través de ella proyectamos también

\footnotetext{
${ }^{3}$ La RAE define "víctima” como una persona sacrificada o destinada al sacrificio, y como un ser que sufre un daño por una causa que le es ajena. Enrique Dussel (1998) reconoce en la víctima este carácter externo y afirma que su existencia es la evidencia de lo injusto de este sistema que somete a unos por interés de otros. La categoría de víctima implica entonces una negación impuesta por otro para afirmar su subjetidad, ese ser dominante no reconoce la dignidad de la víctima, le niega sus derechos y somete a condiciones de dolor y sufrimiento, lo considera de alguna manera un infrahumano, un ser de categoría inferior. En el terreno jurídico la víctima conserva esta exterioridad, se es víctima en la medida en que otro — el sujeto activo - ha hecho una afectación a la persona.
} 
posibilidades de futuro. Es por esto que la memoria resulta un terreno sumamente delicado donde se dan numerosos debates. Tras la firma de los Acuerdos de Paz — en 1996 - trabajar la memoria histórica se volvió en Guatemala una de las tareas a las que se abocaron con más dedicación los distintos actores que estuvieron presentes en la guerra, pues era una manera de posicionarse políticamente frente a ella. Dentro de los numerosos trabajos existentes, Manolo Vela ubica tres paradigmas: el paradigma institucional, el insurgente-contrainsurgente, y el paradigma complejo (Vela, 2011). El primero de ellos consiste en la visión propuesta por los altos mandos - tanto de la guerrilla como de los militares-, quienes elaboraron un discurso en el que ambos aparecían como los actores protagónicos, minimizando la importancia de las bases de uno u otro bando. Del lado del ejército destaca la obra de la Asociación de Veteranos Militares de Guatemala, Guatemala, testimonio de una agresión (1998); y el libro de Mario Mérida, Testigo de conciencia (2000), mismos que reproducen el discurso que los militares tuvieron durante la guerra, es decir, se presentan a sí mismos como héroes que lograron defender a la patria del peligro del comunismo que acechaba a Guatemala, encarnado en los grupos guerrilleros que pretendían cooptar a las poblaciones indígenas mediante la manipulación. Según esta postura, las causas del levantamiento fueron externas al país y formaban parte de una conjura del comunismo internacional.

Dentro de este primer paradigma podemos ubicar también los textos que dan cuenta de la visión de los altos mandos de la guerrilla, entre ellos destacan por supuesto todos los documentos generados por los cuatro grupos guerrilleros, ${ }^{4}$ así como libros autobiográficos que fueron publicados por los dirigentes en distintos momentos. Éstos van desde los primeros textos de Mario Payeras, Los días en la selva, publicado por primera vez por Casa de Las Américas (1981), así como El trueno en la ciudad... (1987); pasando por el libro de César Montes, Mi camino fue la guerrilla (Macías, 1998); Santiago Santa Cruz, Insurgentes. Guatemala, la paz arrancada (2004), hasta llegar a la

\footnotetext{
${ }^{4}$ El Partido Guatemalteco del Trabajo (PGT), las Fuerzas Armadas Revolucionarias (FAR), el Ejército Guerrillero de los Pobres (EGP) y la Organización Revolucionaria del Pueblo en Armas (ORPA).
} 
reciente publicación del Comandante Pancho, Sierra Madre: Pasajes y perfiles de la guerra revolucionaria (Palma Lau, 2010).

Tanto en los textos del ejército como en los de los altos mandos guerrilleros se niega la agencia de la población civil. Los primeros presentan al común de la sociedad como una masa inconsciente engañada por la guerrilla, mientras que los segundos lo hacen como una base de apoyo en abstracto, sin detenerse a explicar sus propios procesos políticos, pues se presentan a sí mismos como la vanguardia revolucionaria. Los objetivos de reconstruir estas memorias no son los mismos para un grupo que para el otro, la guerrilla buscaba — sobre todo en los primeros textos- convencer a la población de unirse a su causa enalteciendo su justeza, es decir, son textos propagandísticos, lo que nos explica toda la aureola de heroísmo contenida en los relatos. Por su parte los militares escriben hasta después de la firma de paz y lo que buscan es dejar en claro que el aparato represivo fue tan brutal debido a que existía un peligro mayor para el país.

Sin embargo hay algo que sí comparten ambas narrativas y es la intención de justificar su papel dentro de la guerra. Al hacerse un mutuo reconocimiento, guerrilleros y militares, explicaban lo sucedido en un marco de guerra, donde había enemigos, posiciones y batallas. En este contexto, el estado de excepción se vuelve la regla, por lo que muchas de las acciones cometidas son disculpables y pueden gozar de amnistía. ${ }^{5}$

El segundo grupo de textos, que Vela denomina "paradigma insurgente-contrainsurgente”, implica también la reducción de la guerra a una lucha frontal entre dos actores que habrían dejado a la población atrapada entre los dos frentes de guerra. El principal exponente de esta visión fue el antropólogo norteamericano David Stoll, quien publicó su controvertido libro sobre las poblaciones ixiles (1999). Esta postura no tomaba en cuenta la disparidad en cuanto a la cantidad de armamento, soldados y aliados, tampoco consideraba las causas por las que se habían gestado las guerrillas ni los motivos que llevaron a la gente a integrarse a estos ejércitos. Afirmaba de manera categórica que la

${ }^{5}$ Con base en el artículo 2 de la Ley de Reconciliación Nacional firmada el 27 de diciembre de 1996 Decreto 145-1996. Para ampliar información revisar http:// www.libertopolis.com/wp-content/files/Ley_de_Reconciliacin_Nacional_Dto-_ Ley_145_96.pdf [fecha de consulta: 17 de junio de 2013]. 
mayoría de la población había sido obligada o presionada para participar ya fuera como combatiente de la guerrilla o como patrullero del lado del ejército. Esta hipótesis de los dos demonios, llamada también Teoría del sándwich (Taracena, 2007), fue promovida por el Estado militar pues implicaba reducir la inconformidad a un mínimo de la población. Al negar que los pueblos hubieran participado de manera activa se reducían las causas de la guerra y se desacreditaba el potencial revolucionario de las comunidades.

Sorprende que actualmente esta postura de los dos demonios siga siendo defendida por importantes actores que se centran en el tema de la memoria, como es el caso del proyecto "Memorial de la Concordia" ${ }^{6}$, encabezado por ex combatientes de la guerrilla, activistas, empresarios, así como por un general retirado, Julio Balconi. Veo con recelo este proyecto pues parte de la premisa de que la gran mayoría de la población fue víctima pasiva de una violencia que le era ajena: el memorial contempla poner a la par a las personas que murieron en manos del ejército y a las que sucumbieron por las armas de la guerrilla. Aunque hay un reconocimiento de que el grado de violencia no es el mismo se concibe a todos los muertos como víctimas de la guerra sin importar el papel desempeñado en ella. En palabras de Gustavo Meoño — quien fuera dirigente del EGP y hoy está al frente del Archivo Histórico de la Policía Nacional además de formar parte del proyecto del Memorialpodemos leer con claridad cómo se mantiene esta postura:

Las víctimas de la violencia están en todos lados; no podemos reducirlas a un ámbito social, político, económico o ideológico. Tanto el Estado como la insurgencia violaron los derechos humanos durante el conflicto armado interno. Ello nos ha llevado a un grupo de ciudadanos a plantearnos la necesidad de encontrar una

\footnotetext{
${ }^{6}$ El Memorial de la Concordia contempla cuatro proyectos: una Plataforma virtual de la Memoria, que está en vigencia desde 2014 e incluye archivos, bases de datos, testimonios y documentos de la Guerra; El Mapeo de la Memoria, que consiste en localizar los lugares de la memoria existentes en Guatemala; Diálogos Intergeneracionales y Jornadas de la Memoria, que se realizan continuamente, y finalmente la construcción de un Centro Cultural de la Diversidad, cuyo proyecto arquitectónico está pero no se ha llevado a cabo.
} 
salida para evitar estar condenados a esta especie de cadena perpetua a la confrontación permanente (Meoño, 2012: 26).

Vemos en esto la permanencia del discurso que se impulsó en los Acuerdos de Paz y que implica, bajo la bandera de la reconciliación, dejar atrás las disputas que motivaron la guerra, reduciéndola a una confrontación ideológica entre dos grupos y minimizando el carácter estructural de las causas que hoy siguen vigentes en el país.

La teoría de los dos demonios fue reivindicada por varios académicos (Rouquié, 1994; Le Bot, 1995; Bataillon, 2008; Sabino, 2008). Pero fue también sumamente debatida por numerosos actores que forman parte de lo que Vela nombra como "paradigma complejo", que implica una visión más complejizada de los hechos en la que no hay dos actores confrontados sino un entramado de sectores sociales que se entrecruzaron en el marco de la guerra, éstos venían de procesos históricos propios de luchas y resistencias. ${ }^{7}$ Se reconoce la larga trayectoria de combate de los pueblos indígenas desde siglos atrás, así como la particularidad del movimiento sindical o las reivindicaciones de las mujeres antes, durante y después de la guerra.

El grueso de la población no aparece más como víctima pasiva sino como sujeto protagónico del devenir histórico, se presentan entonces actores importantes como los estudiantes universitarios, que aunque simpatizantes no eran necesariamente miembros de las guerrillas, o bien otros sectores como los religiosos de base y los campesinos cooperativistas, que participaban de las movilizaciones sociales pero no necesariamente de la insurgencia armada. Este análisis más complejizado permite también visibilizar las contradicciones existentes dentro de un mismo sector, como por ejemplo el de los pueblos indígenas, pues en una misma comunidad e incluso al interior de las familias podían existir quienes hubieran optado por sumarse a la guerrilla, quienes eran meros simpatizantes, así como otros que decidían mantenerse al margen o por el contrario tomaban la decisión, a veces forzada pero otras

\footnotetext{
${ }^{7}$ Se entiende como resistencia la capacidad de los sujetos para oponerse a la imposición social que sobre ellos ejercen las clases opresoras, que puede variar en métodos pero que implica necesariamente una acción.
} 
voluntaria, de sumarse a las Patrullas de Autodefensa Civil o de fungir como delatores de los combatientes.

Por otra parte, este paradigma implica también el reconocimiento de las causas estructurales que desataron la guerra, esto es, deja de presentarse como un capricho de un grupo de revolucionarios para reconocer los motivos de fondo que llevaron a la población a participar, como las condiciones de desigualdad existentes en el país, la falta de tierras de los campesinos, la exclusión y marginalidad de los pueblos indígenas, la represión política a cualquier forma de organización, incluido el movimiento cooperativista.

\section{Límites en la construcción crítica de la memoria}

Dentro del paradigma complejo de la memoria existen también muchas limitaciones que me interesa poner a la luz como una manera de contribuir a un análisis crítico de la guerra. Quiero para ello hacer la revisión de algunas obras y experiencias enfatizando en cuatro temas: las causas que motivaron la guerra; los actores involucrados en ella; los propósitos mismos de la recuperación de las memorias y, por último, la posición que suele fijarse con respecto a la participación activa o pasiva de los distintos actores. Este último tema, que he definido como la trampa de la victimización, es el objetivo central del presente artículo.

Dentro del mencionado universo historiográfico crítico organicé cuatros grandes grupos para su análisis. El primero está compuesto por los informes realizados al poco tiempo de la firma de la paz. El segundo lo forman trabajos de recuperación de la memoria histórica desde lo local, partiendo de las particularidades de cada región. En el tercero agrupé memorias construidas de y desde las mujeres. Por último, me avoqué a los procesos de recuperación de memorias de hijos e hijas de los militantes revolucionarios.

El informe Guatemala: Nunca Más impulsado por la Oficina de Derechos Humanos del Arzobispado de Guatemala (ODHAG, 1998) fue presentado en abril de 1998. Unos meses después, en febrero de 1999, la Comisión de Esclarecimiento Histórico (CEH), creada en el marco de los Acuerdos de Paz, presentó Guatemala: Memoria del silencio (CEH, 1999). Ambos trabajos tenían por objetivo romper los silencios impuestos por los discursos del poder y 
permitir la emergencia de la voz de los sujetos que habían sufrido la violencia, para ello se recolectaron testimonios por todo el país.

Debido al escenario de terror que se vivía en Guatemala fue necesario generar condiciones de confianza que permitieran a la gente hablar, en esto resultó fundamental la estructura de trabajo pastoral con que contaba la Iglesia católica en los distintos departamentos. Los testimonios que se obtuvieron en ambas experiencias han posibilitado llevar a cabo procesos de justicia y son sin duda un referente al cual se debe acudir para realizar cualquier investigación sobre el periodo. Sin embargo, ya que fueron recogidos en contextos de mucha urgencia y respondiendo a formatos cerrados de entrevistas, para los testigos no fue posible profundizar en ciertos temas. El ejemplo más claro de ello es la violencia dirigida contra las mujeres en el marco de la guerra, de la que apenas se hace mención en los informes, lo que responde por un lado a un silenciamiento del tema en las propias sobrevivientes pero también a que las preguntas no fueron guiadas hacia la profundización de estas situaciones ni se hicieron recomendaciones al respecto (Fulchiron, 2006).

Al centrar los testimonios en la descripción detallada de los hechos de violencia - lo que sin duda tiene un fuerte valor jurídico — dejan de lado las memorias de lucha y resistencia de los pueblos que aparecen enunciados como víctimas. Aunque los informes dejan en claro la desproporción entre la violencia del Estado y la de la guerrilla, existe en esta figura de la víctima un punto de encuentro que oculta la complejidad de los hechos históricos y que simplifica nuevamente el papel desempeñado por los distintos actores. Al llegar a la narración de la represión se desdibujan otras formas organizativas y termina por ponerse el foco en los grupos guerrilleros, invisibilizando así las estrategias que posibilitaron a los pueblos resistir ante la atroz violencia.

Es clara la pertinencia de la denuncia que hicieron los informes al ser los primeros trabajos que se realizaron después de terminada la guerra, sin embargo precisamos enunciar esta limitación para poder superar los vacíos que dejaron. Del mismo modo resulta necesario entender que al pertenecer al contexto de los Acuerdos de Paz — en el que se creía que el tránsito a la democracia era posible-, el perdón y la reconciliación aparecen como los objetivos finales de la recuperación de la memoria histórica. La Comisión de Esclarecimiento Histórico $(\mathrm{CEH})$ es más crítica a este respecto y afirma que para poder alcanzar 
la transición social es necesario impulsar procesos de búsqueda de justicia, sin embargo no plantea la forma de cómo pudieran llevarse a cabo. Esto se debe a que desde su conformación la CEH estaba limitada a no fincar responsabilidades específicas ni a emprender procesos judiciales, por un acuerdo firmado entre el gobierno y la guerrilla ${ }^{8}$ para protegerse mutuamente y que a decir de Grandin "el documento de una página que constituyó a la comisión fue una idea de último momento acordada por los debilitados líderes de la guerrilla y los comandantes de las Fuerzas Armadas triunfantes" (Grandin, 2007), por tanto no alcanzó la profundidad que hubiera sido necesaria para realmente generar una transformación social.

En cuanto a las causas de la guerra, el informe de CEH señala el carácter estructural de un Estado racista, autoritario y excluyente, además de reconocer las raíces económicas estructurales que originaron la subversión, incluyendo cifras que demuestran la situación de desigualdad. Sin embargo, lo que aún está ausente en el informe es la explicitación de los intereses geoestratégicos que representaban para las clases oligarcas los territorios donde se dieron las masacres y se hicieron los desplazamientos para dejar el terreno libre a la explotación de los recursos naturales, tampoco existe en el informe un análisis del papel que jugó Guatemala a nivel internacional. Podemos afirmar, entonces, que en los documentos existe un primer intento por mirar las raíces de la guerra, pero es preciso hilar mucho más finamente para verdaderamente entender lo que estuvo detrás del genocidio que se dio en los pueblos.

\section{Memorias locales}

Los trabajos de recuperación de la memoria histórica que han partido desde lo local han logrado avanzar bastante en este objetivo, para esta revisión me centré en los textos del sacerdote Ricardo Falla (1992), de Margarita Hurtado Paz y Paz (2009), los artículos compilados en el libro Desafios y potencialidades de la historia local de Guatemala, de la Asociación para el Avance de las Ciencias Sociales (Mendizábal, 2005), así como la labor realizada por la Iniciativa para la Reconstrucción y Recuperación de la Memoria Histórica en

\footnotetext{
${ }^{8} \mathrm{Me}$ refiero al Acuerdo sobre el establecimiento de la Comisión para el Esclarecimiento Histórico de las violaciones a los derechos humanos y los hechos de violencia que han causado sufrimientos a la población guatemalteca, firmado por representantes del gobierno y de la Unidad Revolucionaria Nacional Guatemalteca en Oslo, Noruega, el 23 de junio de 1994.
} 
el departamento del Quiché (IRRMH, 2012), y un trabajo de recuperación de la memoria realizado por el Museo Comunitario de Rabinal Achí, Baja Verapaz (Bert, 2003).

El jesuita Falla hizo sus primeros trabajos basados en la recopilación de testimonios en campamentos de refugiados en México. Su objetivo al recrear los hechos no era regodearse en el dolor sino destacar en estos relatos la forma como las poblaciones lograron sobrevivir y soportar los embates de un ejército que pretendía eliminarlas y terminar con su identidad. Falla logra ubicar dentro de estos testimonios las historias de resistencias que narran cómo los pueblos lograron sobrevivir a tanto horror, poniendo en alto la dignidad y por tanto consiguiendo de alguna manera su afirmación como sujetos: "estos testimonios son una buena noticia porque afirman que los pobres y débiles pueden vencer esa estrategia de violencia y pueden resistir a las técnicas que dividen lo más íntimo de la persona, que es su identidad y lealtad" (Falla, 1992: 33).

Los testigos que refiere Falla repiten constantemente una verdad: "sobreviví y estoy vivo". Este tipo de memorias son las que dan la fuerza para construir el futuro, porque si estas personas pudieron subsistir con todo en contra y organizarse como lo hicieron al formar las Comunidades de Población en Resistencia (CPR) ${ }^{9}$, ¿qué no serán capaces de hacer?

Con estas memorias de resistencia se complejizó la historia de la guerra y se abrió la posibilidad de dar un salto más en la reflexión de lo sucedido y pensar cuál había sido el papel de las comunidades en el desenvolvimiento de los hechos. En el norte del Quiché se formó en 2002 la Iniciativa para la Reconstrucción y Recuperación de la Memoria Histórica (IRRMH) que reunía personas de las CPR de la Sierra y gente que vivió en los campamentos de refugiados, así como algunos reasentados de la costa sur; esta iniciativa es acompańada y apoyada por algunas personas de la ciudad de Guatemala que aportan herramientas metodológicas para realizar el trabajo de recuperación. El objetivo primordial de este grupo es dejar plasmada su memoria, contar

\footnotetext{
${ }^{9}$ Las CPR son comunidades que fueron formadas en la huida de los bombardeos y la persecución del ejército. Las poblaciones se refugiaron en la montańa y comenzaron a organizarse primero simplemente para sobrevivir, y al paso de los años para generar, aun en estas condiciones, sistemas de salud, educación y producción. Las CPR salieron a la luz pública con este nombre el 7 de septiembre de 1990, se encontraban en tres áreas de Guatemala: La Sierra del Quiché, conocidas como CPR Sierra; la selvas del Ixcán, conocidas como CPR Ixcán; y en la selva petenera, conocidas como Comunidades Populares en Resistencia del Petén.
} 
su propia historia para que quede como un legado a las generaciones que hoy siguen luchando contra los megaproyectos. Se acude a las memorias para encontrar lecciones sobre las formas en que esos mismos pueblos resistieron en el pasado que ayudan a entender sus condiciones actuales. El resultado de este trabajo se puede leer en el libro Nuestro entendimiento común sobre la historia de nuestras tierras, nuestros pueblos y nuestras resistencias que reconstruye la historia a través de la memoria de los pueblos, este esfuerzo "recupera la voz y la fuerza de los verdaderos protagonistas: los pueblos en resistencia. No como víctimas. Ni como comparsas de un enfrentamiento entre actores armados. Sino como los sujetos fundamentales en una epopeya que dura más de 500 años" (IRRMH, 2012: 89).

Otro esfuerzo colectivo es el que está detrás del libro Oj K'aslik. Estamos vivos... (2003), sobre la experiencia en Rabinal, en el departamento de Baja Verapaz, donde sucedió la terrible masacre de Río Negro el 13 de marzo de 1982: murieron 177 mujeres y niños. El texto se centra en la historia de sobrevivencia y lucha de estos pueblos basándose en los testimonios de quienes vivieron la guerra, poniendo especial acento en su particularidad como pueblo maya-achí. El estudiar la guerra contrainsurgente desde la dimensión local permite centrar los relatos en los procesos históricos de los propios pueblos que les llevaron a participar de manera activa. El texto $O j K^{\prime}$ aslik... propone como un antecedente fundamental de la guerra la época de la dictadura del general Jorge Ubico — que gobernó de 1931 a 1944—, ya que fue durante su periodo que se establecieron la Ley contra la Vagancia y la Ley de Vialidad, ambas obligaban a los indígenas y jornaleros a trabajar de manera forzosa. Ante esa imposición, los achíes ${ }^{10}$ del lugar realizaron acciones de desobediencia y lograron resistir.

Otro antecedente lo sitúa en la fundación de la Comunidad de Campesinos y del Sindicato de Obreros durante la primavera revolucionaria, de 1944 a $1954,{ }^{11}$ que lograron mantenerse tiempo después pese a la represión del Estado.

${ }^{10}$ Los achíes o achi'son un grupo indígena maya ubicado en el departamento de Baja Verapaz, Guatemala.

${ }^{11}$ Se conoce como la primavera revolucionaria a los gobiernos de Juan José Arévalo (1944-1950) y Jacobo Arbenz (1950-1954), ya que se implementaron profundas reformas sociales que pretendían transformar las condiciones socioeconómicas del país. Entre ellas la Ley de Seguridad Social de 1946, el Código del Trabajo de 1947, y sobre todo la Ley de la Reforma Agraria de 1952. En 1954, Arbenz fue obligado a renunciar 
Para el caso del pueblo ixil, al norte del Quiché, IRRMH utiliza un método similar al de Rabinal, rastrea en el legado de la memoria histórica de las comunidades los elementos de lucha y resistencia. Ubica los orígenes del pueblo ixil en la época prehispánica, destacando algunos elementos culturales que perviven hasta hoy, pese a la opresión y despojos que han sufrido los pueblos desde la llegada de los espańoles. El conflicto por la tierra es entendido como un eje que atraviesa la larga historia de los ixiles, comenzando por el Decreto 170 que en 1877 estableció por primera vez que las tierras baldías podían ser dadas en subasta, lo que justificó el despojo a manos de los liberales. Esta situación se mantuvo hasta la Reforma Agraria de 1952, cuando mediante el Decreto 900 se protegió a las comunidades. Sin embargo, a la caída del gobierno revolucionario esto se vino abajo y unos años después, en 1970, el general Carlos Arana Osorio aprobó el Decreto Ley 60-70, que dio luz verde al proyecto Franja Transversal del Norte, mismo que atraviesa una zona de enorme riqueza natural. Este decreto abrió además el espacio a las inversiones petroleras y mineras que siguen afectando las poblaciones.

En cuanto a la parte organizativa, IRRMH concibe la importancia que tuvieron en las comunidades los movimientos de conversión religiosa, como el de Acción Católica (AC), que permitieron romper con el costumbrismo dominante desembocando en movimientos organizativos para resolver los problemas inmediatos de productividad mediante la instauración de cooperativas y ligas campesinas, generando un nuevo modelo de desarrollo comunitario. Estas iniciativas de los ańos 50 y 60, si bien eran procesos organizativos y por tanto políticos, no estaban ligadas a factores externos ni vinculadas con la guerrilla, sin embargo fueron espacios de formación política para los pueblos.

Por su parte, Margarita Hurtado ${ }^{12}$ se centra en la región de Huehuetenango, por medio del análisis de testimonios y documentos busca reconstruir "la memoria colectiva de la lucha revolucionaria” (Hurtado, 2009: 32) para lograr entender el proceso histórico en toda su complejidad. En este texto la autora defiende y argumenta la existencia de una participación activa y masiva de las comunidades en la guerra luego de que EGP se extendiera en la zona mediante la estrategia de guerra popular revolucionaria, que implicaba un protagonismo

tras una ofensiva militar liderada por Estados Unidos, como consta en el documento PB SUCCESS.

${ }^{12}$ Quien fuera durante la guerra líder combatiente del Ejército Guerrillero de los Pobres. 
de las poblaciones y un rompimiento con la tradición de vanguardias revolucionarias. Asimismo destaca la participación indígena en las ofensivas lanzadas en 1981 contra patrullas del ejército, en operaciones de recuperación de armamento y en las disputas por terrenos en varias regiones de Huehuetenango.

Todos estos textos coinciden en señalar que el encuentro entre la guerrilla y las poblaciones fue un proceso histórico natural porque existía una "coincidencia entre el planteamiento revolucionario y el descontento y cansancio acumulados en la población local ante tanta injusticia sufrida por generaciones" (Hurtado, 2009: 40). Esta visión reivindica la agencia de los ixiles, oponiéndose a la postura de Stoll que los reducía a víctimas pasivas de la guerra que a decir de Hurtado "refleja una profunda subestimación de la capacidad de las personas para comprender la situación de injusticia en la que viven y su capacidad de rebelarse para buscar el cambio social" (ídem: 62). La participación de la población no puede negarse de ninguna manera y resulta inútil tratar de minimizar su papel, pues las luchas de hoy son la muestra clara de que el pueblo guatemalteco es consciente y está activo. Ahora bien, es importante destacar que los indígenas no solo tuvieron un papel activo del lado de la lucha revolucionaria y los movimientos sociales, también participaron en las Patrullas de Autodefensa Civil y como comisionados militares, muchos de ellos obligados por el ejército para formar parte de estas estructuras, sin embargo también hubo quienes participaron por decisión propia al encontrar ahí una fuente de recursos económicos o de posición social. Si nos negamos a reconocer esto no podemos entender la complejidad de la guerra, pero sobre todo del fracaso de la reconciliación, pues estos actores continuaron ejerciendo poder al interior de las comunidades aun después de firmada la paz.

El recuperar la memoria histórica desde una perspectiva local permite entender la guerra en su complejidad, pues deja de manifiesto los intereses geoestratégicos que estaban detrás, como bien afirma en entrevista Javier Gurriarán, integrante de IRRMH: "Cada área, cada lugar masacrado o desocupado por la fuerza militar de población en este momento está reocupado por compañías internacionales" (entrevista a Javier Gurriarán, Guatemala, 19 de noviembre de 2013). Esto no sólo ocurrió en el Quiché, también en Rabinal, donde existe una clara relación entre las masacres de Río Negro y un megaproyecto en la zona para construir la presa hidroeléctrica de Pueblo 
Viejo-Quixal, que afectaría a Rabinal y Cubulco. Al tiempo que el ejército estaba arrasando a la población se comenzó a cimentar la presa.

En la época actual son numerosos los proyectos que invaden los territorios por donde ayer pasó la guerra. Las hidroeléctricas y las mineras siguen buscando la manera de segregar a las poblaciones de sus territorios para apropiarse de sus recursos. ${ }^{13} \mathrm{El}$ gobierno ha apoyado estas iniciativas criminalizando a los líderes sociales y encarcelándolos, vemos entonces que si bien han cambiado las estrategias, el Estado sigue siendo cómplice del despojo a las poblaciones, sin consultarles sobre el futuro que quieren en sus territorios. Pero como en el pasado, las comunidades no se quedan de brazos cruzados, sino que emprenden nuevas luchas ya no por la vía de las armas, ahora mediante la organización en defensa de sus recursos haciendo uso de la memoria colectiva, que les recuerda cómo lucharon en otros hostiles tiempos.

\section{Memoria de y desde las mujeres}

En este afán por visibilizar las particularidades de los distintos actores que participaron en la guerra, existen esfuerzos que se han dado a la tarea de recuperar la memoria histórica de y desde las mujeres. Entre ellos seleccioné para el análisis el trabajo realizado por el Consorcio Actoras del Cambio (Fulchiron y otras, 2009), el colectivo Kumool (Hernández y otras, 2008), así como las investigaciones de Silvia Soriano (2006) y Ana Silvia Monzón (2005).

Mirar la historia desde las mujeres implica prestar atención a situaciones y particularidades que se pierden en las historias oficiales y aun en los procesos de recuperación de la memoria que buscan abarcar generalidades que terminan por invisibilizarlas. Siguiendo a Monzón podemos afirmar que a las memorias de las mujeres, como a las de los pueblos mayas, se les menosprecia porque son consideradas parciales, se afirma que no ven más que una parte del escenario y que por tanto no pueden aspirar al paradigma de lo universal, pero resulta que ese universal es siempre masculino, blanco, y de cierta clase social. No es por tanto el paradigma que perseguimos cuando construimos memorias, sino uno mucho más complejo que contemple las particularidades y fragmentaciones.

${ }^{13}$ Para ampliar esta información refiérase al capítulo "La paz, el reordenamiento actual. Planes de desarrollo, megaproyectos y compañías transnacionales", en Iniciativa para la Reconstrucción y Recuperación de la Memoria Histórica (2012), Nuestro entendimiento común sobre la historia de nuestras tierras, nuestros pueblos y nuestras resistencias, Coordinación por los Derechos de los Pueblos Indígenas, Ciudad de Guatemala. 
Al estudiar la memoria de las mujeres, la primera pregunta que se presenta es el porqué de esta violencia dirigida contra ellas. Al tratar de responderla, las mujeres han compartido sus recuerdos más íntimos para lograr de manera colectiva explicarse lo ocurrido en la guerra; es decir, han podido transitar de una memoria individual muy dolorosa al ejercicio de una memoria histórica clarificadora.

La violencia que ejerció el Estado en contra de las mujeres y sobre todo la violencia sexual quedó grabada en sus cuerpos como un dolor profundo; aun cuando hubieran decido callar o tratar de olvidar para evadir el sufrimiento, los recuerdos volvían en formas muy variadas. A veces se presentaban como pesadillas, otras como un miedo inexplicable, y en muchas ocasiones en forma de enfermedades que evidenciaban que el cuerpo tiene tanta o más memoria que la mente. El hablar de lo que les pasó y acompañarse con otras mujeres que compartían su experiencia les permitió romper el aislamiento en que vivían. En este sentido resulta sumamente valioso el trabajo que ha realizado el Consorcio Actoras del Cambio - junto con otras organizaciones- que ha permitido que las mujeres ubiquen el crimen de la violación en el contexto de la guerra, dejando de sentir que éste es un castigo por algo hecho por ellas o una consecuencia inevitable de su accionar político. El rescate de la memoria colectiva "permite dar una explicación social y política a las atrocidades que vivieron y evidenciar la responsabilidad del Estado en la perpetuación de estos crímenes" (Fulchiron, 2009: 200). Éste es el sentido de rescatar su memoria, poner los hechos en perspectiva, entender las causas de la violencia y ubicar al Estado como responsable, para poder así librarse de la culpa impuesta sobre ellas y fortalecerse como sujetas políticas con una identidad propia.

Por medio de un análisis histórico con perspectiva feminista, lograron dimensionar las raíces patriarcales de las comunidades que provocaban que las personas - mujeres y hombres - atacaran a las mujeres violadas como responsables, atribuyéndoles una culpa que no les pertenecía. Dicho análisis ha permitido desentrañar la forma en que el opresor se interioriza en los pueblos logrando que se sientan responsables de las acciones violentas ejercidas en su contra y que se mantengan las divisiones internas de las comunidades aun sin la presencia de los dominadores. Pero también ha conseguido ver todos los procesos de resistencia que hay dentro de las opresiones. "Nos presenta lecciones sobre la capacidad de resiliencia y el sentido de vida que permitió a 
muchas de estas mujeres mayas sobrevivir ante el desgarramiento de la violencia sexual" (ídem: xviii). En este sentido, la memoria puede volverse un canto a la vida en vez de un recuerdo de muerte y dolor, rescatando la manera en que han dejado de sobrevivir para realmente volver a vivir.

La memoria se vuelve una herramienta de sanación porque permite releer los procesos históricos y transformar el lugar donde obligadamente se las coloca. Muestra de ello es todo el trabajo de recuperación que han realizado las ex combatientes del grupo Kumool, quienes si bien reconocen que pervive en ellas mucho dolor por lo vivido, también están claras de que el proceso ha valido la pena porque les permitió abrir puertas que desconocían y comenzar a transformar la realidad. A muchas les mataron sus familiares y por eso decidieron armarse. Una mujer declara que se unieron a pelear por dignidad, pero aunque fueron a luchar llenas de coraje al ver lo que los soldados estaban haciendo "lograron transitar del odio a una conciencia de lucha, superando los deseos de venganza, así como transformar el temor en una disposición para las actividades político militares" (Hernández y otras, 2008: 81). Y aunque existe en ellas un ligero sentimiento de tristeza por el sueño truncado, hay también una capacidad autocrítica para mirar los errores y los aciertos.

Esta noción se encuentra presente también en los testimonios que recoge el trabajo de Soriano, cuyas protagonistas "valoraron que valía la pena arriesgarse por el resultado esperado" (Soriano, 2006: 7), y que encontraron en el espacio de la lucha revolucionaria un lugar para construir una agencia que no dependiera del esposo o el padre.

La memoria histórica construida desde las mujeres ha aportado una manera de entender la guerra desde las propias sujetas, es decir, que además de llenarse la boca con las generalizaciones de la opresión del sistema capitalista, ha buscado encontrar las causas por las que cada una como individua y en colectivo vivió esta guerra, entender cómo la violencia contra las mujeres se endureció durante la guerra pero no se quedan ahí, en estas memorias vividas existe un hilo que las conecta con sus luchas actuales y cotidianas, con la agresión que aún existe en las comunidades en contra de las mujeres. Las memorias recuperadas les permiten tomar el aliento para levantar la voz y denunciar las injusticias del presente.

El rescate de la memoria busca además romper con el estigma de las mujeres vistas sólo como víctimas, se busca afirmar que las mujeres son mucho más que 
un cuerpo que fue violado, que las mujeres son sujetas de lucha. Sin embargo, es preciso anotar que el dolor de lo vivido ha sido tal que pocas veces se logra recuperar esta dimensión en la memoria de mujeres activas en lucha. Aún es preciso trabajar más en rescatar los relatos de las que combatieron, quienes se enfrentaron a un sistema opresor y propusieron una transformación social de raíz desde las filas de los movimientos sociales o desde las rupturas propias.

\section{Semillas de memoria}

En esta búsqueda por rescatar las historias de lucha y resistencia me encontré con los trabajos de recuperación de la memoria que han elaborado los hijos —de sangre o de ideología - de aquellos que protagonizaron la guerra. Ellos y ellas son la semilla plantada por los combatientes cuyo fruto permite que su lucha siga actual.

Los familiares de los desaparecidos se organizaron en la época de la guerra para exigir al gobierno la presentación con vida de sus seres queridos, en esto fueron pioneras las mujeres organizadas en 1984 en el Grupo de Apoyo Mutuo (GAM), en la ciudad de Guatemala, y en el área rural la Coordinadora Nacional de Viudas de Guatemala (Conavigua), que comienza a reunirse en 1985 y se formaliza en 1988. Estas dos agrupaciones fueron las primeras que de manera organizada hicieron frente al Estado para exigir justicia por los crímenes represivos; antes cada familiar realizaba la búsqueda individualmente. El agruparse les permitió entender la dimensión política de la represión, visibilizarla y sobre todo señalar la responsabilidad del Estado. Para estas dos organizaciones la figura de víctima fue fundamental en la construcción de su narrativa de frente al gobierno y en el terreno judicial; esta posición les permitió evidenciar el uso desproporcionado de la fuerza contra personas no armadas en el campo y la ciudad, y en el caso de Conavigua exigir la reparación del daño después de los acuerdos de paz. Sin embargo, como hemos señalado antes, esta figura tiene el enorme riesgo de negar la agencia en tanto se es víctima por lo que el otro hace sobre el sujeto y no por el sujeto en sí. Considero que el papel de dichas agrupaciones fue fundamental para denunciar los crímenes de Estado y que por tanto son un innegable referente para los procesos de reconstrucción de la memoria, aunque es necesario ser crítica de esta visión victimizadora para poder construir otro tipo de relatos. 
En 1992 se formó otro importante grupo de familiares, la Asociación de Familiares Detenidos-Desaparecidos de Guatemala (Famdegua), quienes también se valen de la figura de la víctima en el terreno jurídico, pues su labor principal ha sido emprender juicios en contra de militares del ejército responsables de las masacres; participaron en el proceso jurídico por la Masacre de Dos Erres, donde se logró sentencia condenatoria a cuatro kaibiles y un teniente militar; y en los juicios por la masacre de Josefinos ocurridos en Libertad, Petén, así como en la masacre de Panzós, éstos se encuentran aún vigentes. Han participado también como querellantes adhesivos en un caso de desaparición forzada. La víctima aparece entonces como estrategia jurídica para emprender los procesos de búsqueda de justicia, es decir, responde específicamente a una finalidad pragmática.

El colectivo Hijos e Hijas por la Identidad y la Justicia contra el Olvido y el Silencio (HIJOS) fue fundado en 1998 por Wendy Méndez, hija de Haydée Méndez, quien fue desaparecida por su participación en el PGT; luego de vivir años exiliada en Canadá regresó a Guatemala tras la búsqueda de su historia, y motivada por su tía Marcia Méndez — directora de Famdeguadecidió formar una organización de hijos de desaparecidos, a manera de la organización HIJOS que existe en Argentina. HIJOS Guatemala salió a la luz pública el 30 de junio de 1999 en medio del desfile militar por el aniversario del ejército, teniendo como ejes de lucha la memoria, la verdad y la justicia (entrevista a Flor de María Calderón, Guatemala, 20 de enero 2013).

En ese mismo año, Kayte Doyle, analista del Archivo de Seguridad Nacional de Estados Unidos, dio a conocer el documento conocido como Diario Militar..., ${ }^{14}$ en el que aparecían 183 fichas de personas detenidas por el ejército. En ellas se daba cuenta del nombre de las personas capturadas, de su pseudónimo, de la organización en la que militaban, el cargo que tenían y sus funciones asignadas. También se consignaba la fecha de su detención y una descripción de la misma; finalmente se anotaba en clave si habían sido ejecutadas y cuándo. El registro lo acompañaban con fotos arrancadas de los documentos de identificación. Al salir a la luz este diario, algunos quienes aparecían en él decidieron organizarse por la petición de justicia. La demanda la retomó el Ministerio Público pero no les dio respuesta, así que en 200528

\footnotetext{
${ }_{14}$ Para ampliar información refiérase a Fundación Myrna Mack (2003), El Diario Militar: Rastros de la verdad. Guatemala.
} 
familias comenzaron una querella en la Corte Interamericana de Derechos Humanos contra el Estado de Guatemala, con el apoyo de la Fundación Myrna Mack.

Entre las personas que aparecían en el Diario se encontraba Amancio Samuel Villatoro con el número 55, que había sido detenido en 1984 y cuyo cadáver fue encontrado en una exhumación realizada en el destacamento militar de San Juan Comalapa, departamento de Chimaltenango, junto al de Sergio Saúl Linares Morales, Juan de Dios Samayoa Velásquez, Hugo Adail Navarro Mérida y Moisés Saravia López (Doyle, 2011). El cuerpo de Villatoro fue identificado por la Fundación de Antropología Forense de Guatemala (FAFG) mediante una prueba de ADN en 2011. La familia no supo qué hacer con los restos, pues tenía distintas opiniones, y ante el ofrecimiento del director Fredy Peccerelli, de la FAFG, de prestarles un espacio para mantener el cuerpo y que lo pudieran visitar, fue surgiéndoles la idea de crear un museo donde se rescatara la historia de Samuel Villatoro, así como la de los desaparecidos del Diario Militar (entrevista a Samuel Villatoro, Guatemala, 6 de noviembre de 2012). Fue así como el 30 de enero de 2012 abrió sus puertas el Museo de los Mártires del Movimiento Sindical, Estudiantil y Popular de Guatemala, en donde se presentan los restos encontrados y se explica someramente la represión selectiva ocurrida durante la guerra. ${ }^{15}$

Lo novedoso en la propuesta de memoria histórica de estos hijos y familiares de los combatientes es que se acercan a la historia de la guerra con una pregunta que nadie se había atrevido a formular de manera clara y contundente: ¿por qué se luchaba y cuáles de esas causas siguen vigentes hoy?

En trabajos anteriores se habían realizado esfuerzos por explicar las raíces históricas y económicas que llevaron a la población a insurreccionarse, así como por ubicar las problemáticas locales que posibilitaron la emergencia de la lucha revolucionaria. Sin embargo, los motivos que tenían los combatientes apenas se habían analizado al estudiar los proyectos revolucionarios y siempre fueron circunscritos en una lógica de otro tiempo, en un contexto de guerra fría, en una oleada de guerrillas en América Latina. Y sobre todo, los esfuerzos se habían consignado a entender el porqué de la violencia y el funcionamiento

${ }^{15}$ Para más información sobre el proceso de constitución del Museo refiérase a De León, Quimy y Nelton Rivera, "Todo está cargado en la memoria: un museo para no olvidar", Prensa Comunitaria, 20 de mayo de 2014, en https://comunitariapress.word-press. com/2014/05/20/todo-esta-cargado-en-la-memoria-un-museo-para-no-olvidar/ 
de las estructuras de Estado que la permitieron. Es preciso denunciar el horror vivido y exigir justicia, pero es igualmente necesario razonar sobre los motivos de la insurrección, sobre los aciertos y los errores cometidos por las guerrillas; es preciso rescatar de ellos ese germen transformador que le generó tanto miedo al gobierno, no para lanzarse a la lucha por los mismos medios pero sí para encontrar la manera de darle continuidad a eso que se considera justo.

Esta perspectiva de la memoria consiste en defender el papel activo de los sujetos que participaron en la guerra, se opone de manera tajante a la teoría de los dos demonios que niega la acción consciente de los pueblos y afirma que incluso aquellas poblaciones que en un inicio tomaron la decisión de mantenerse al margen, como muchos indígenas, en el transcurso de la guerra tuvieron que organizarse para garantizar su sobrevivencia, como es el caso de las personas que formaron las Comunidades de Población en Resistencia.

Los hijos - herederos del legado de la memoria histórica- toman la palabra para afirmar que el pueblo actuó de manera concienzuda, que no fue un arranque de rabia ni el producto de una manipulación externa. Asumen que la violencia ejercida por el Estado fue desmedida y que el horror infringido a sus familiares debe ser castigado, pero se niegan a quedarse atrapados en la figura de la víctima que invisibilice la acción de los luchadores sociales. El dolor de la pérdida y angustia de la incertidumbre sólo son aminorados por este recuerdo de vida; los familiares — pero sobre todo los hijos — necesitan reconstruir una figura de sus padres ausentes para hacerse de un referente con el cual crecer, al cual admirar, no les sirve entonces una figura de un ser sufriente ni el recuerdo permanente de su ausencia, necesitan recordarlo con vida aunque no lo hayan conocido, saber que ese padre, esa madre, ese tío tenían ideales y sueños que pueden heredarles aun en esta ausencia. Es probablemente esta búsqueda lo que llevó a HIJOS a rescatar los relatos de vida por encima de la muerte.

Sin embargo, es necesario decir que aunque la intención sea el rescate de la memoria de la vida y de la lucha, no en todos los esfuerzos se ha logrado que palpite la vida. Se han elaborado numerosos memoriales donde se rescata el nombre de los desaparecidos y asesinados que resultan impactantes pero, que más allá de esa primera impresión, no logran romper con el anonimato, son una manera más de acumular cifras. Soriano hace una crítica muy interesante a estos monumentos del terror que en pos de recordar a los caídos enaltecen su condición de víctimas generando martirilogios. A propósito del monumento 
de las víctimas de la masacre de Acteal, Chiapas, llamado Columna de la Infamia, nos dice que es

\begin{abstract}
un monumento que no hace referencia a la lucha por el esclarecimiento de los hechos o por la justicia siempre tan postergada, sino que refuerza la angustia que se mira en los rostros esculpidos, un monumento que hace honor a la desolación y finalmente a "los mártires", a las "víctimas", a los que murieron rezando pero no a los que luchan, no a los que viven y/o mueren luchando (Soriano, 2004: 244).
\end{abstract}

El horror sucedió, no debe ser negado, pero es importante que no se alabe la muerte por encima de la vida. Necesitamos que se sepa que esas personas antes de ser víctimas de la guerra eran seres como cualesquiera de nosotros, que tomaron decisiones y que participaron de algún u otro modo en el desenvolvimiento de los hechos, y destacar las razones que los llevaron a luchar, la intenciones que tenían de transformar las condiciones de la población, la apuesta era por la vida y es la vida por tanto la que debemos honrar y recordar.

En el discurso de los familiares se ha logrado romper con esta idea de la víctima, pues se afirma el papel activo que jugaron en la guerra y con ello se enaltece su dignidad. Esto en sí mismo tiene un gran valor, pues quiebra una larga tradición de silencios familiares que había llevado a muchos a la decisión de no hablar con claridad de la militancia de los desaparecidos, por el miedo que esto generaba. Cuando HIJOS y los familiares del Diario Militar comenzaron a reconocer que sus desaparecidos sí eran gente organizada y armada, se empezó a romper la idea de que la lucha es motivo suficiente para ser asesinado. Sin embargo, considero que en el caso del Museo de los Mártires aún deja la sensación, en el visitante, de que lo mejor para evitar la muerte es no inmiscuirse en asuntos políticos. Esto se debe probablemente a que se trasmite todo el terror que se vivió en la época de la guerra, pues nuevamente se centra la atención en la violencia por encima de los aportes de la lucha revolucionaria.

No obstante, podemos afirmar que lo que logran estas memorias de los hijos es devolverle el rostro a los desaparecidos y asesinados. No permitir que sigan siendo un XX enterrado en el cementerio de la Verbena. Restituirles su carácter de sujetos con nombre y apellido, con una historia, con ideas y con muchos lazos afectivos que dejaron huérfanos. Ésa es la memoria de la dignidad que 
buscan rescatar porque no quieren que los muertos y desaparecidos pasen a la historia como criminales por haber luchado y tenido sueños. Los criminales son aquellos que los desparecieron y su encarcelamiento será una forma de romper con el carácter de víctimas que les han impuesto, de devolverles la justicia y la dignidad a los muertos y a todos los vivos. Para denunciar esto, los HIJOS empapelan la ciudad para que al caminar por ella nos demos cuenta de que aquel que falta podría ser cualquiera, un primo, una amiga, un vecino, una hermana, una madre, que ya no está. Esto permite humanizar la historia, entender que la guerra no fue una épica de grandes batallas salida de una novela de aventuras, sino una lucha que dio gente como nosotros en su vida diaria, en la calle, en el trabajo, en la escuela. Gente de carne y hueso que se organizó porque la situación era insostenible y decidió hacer algo para cambiarla.

Sin duda alguna la memoria de los hijos representa un paso hacia la recuperación de las historias de lucha y resistencia, es un camino en el que hay que continuar. Si la represión del ejército fue tan brutal, si mataron a la gente con tanta violencia fue para instaurar el miedo, para acallar generaciones enteras, para mantener el control. Si silenciamos las victorias y sólo nos queda el recuerdo de las derrotas al final lograrán el objetivo. No se deben callar las muertes que sucedieron en el pasado, pero mucho menos callar las vidas. Las memorias de estas personas que lucharon deben también ser rescatadas y recordadas con la dignidad y la frente en alto, pero sobre todo deben rescatarse de ellas los sueños que les valieron la vida. Como dirían Horkheimer y Adorno para nuestras historias y nuestras memorias: "la tarea por cumplir no es la conservación del pasado sino la redención de la esperanza del pasado” (1994).

\section{Conclusiones}

Podemos afirmar que la recuperación de la memoria no es en sí misma emancipadora, por el contrario puede ser utilizada para justificar hechos atroces, para silenciar las voces de otros y restarles protagonismo al reducirlos a la condición de víctimas pasivas. Pero si bien puede ponerse al servicio de la dominación, la memoria es también una herramienta para la emancipación porque nos permite jalar los hilos de las luchas pasadas, encontrar la fuerza que viene de atrás y que nos demuestra que las disputas que tenemos hoy ante las embestidas del poder, del neoliberalismo, de la opresión, del patriarcado, no son nuevas, y que antes como ahora hemos logrado subsistir y salir adelante. 
La memoria que va más allá del dolor y la victimización y recupera las vivencias de lucha nos permite asumirnos como sujetos protagónicos capaces de realizar profundas transformaciones sociales.

En las distintas experiencias revisadas podemos observar algunas pistas de cómo romper con una memoria que está centrada en la victimización y construir relatos donde todos los actores sociales tengan una agencia definida. En los procesos de construcción de la memoria a través de lo local reconocemos una potencia para ello, pues el ver los hechos desde la dimensión de la comunidad permite complejizar la historia, ubicar bien a los actores y entender también las contradicciones existentes que nos permitan distanciarnos de una visión binaria de buenos y malos. Al estudiar las comunidades indígenas a fondo podemos desmontar por ejemplo la idea de que todos los patrulleros que sirvieron al ejército lo hicieron de manera obligada y reconocer que, aunque hubo esta imposición en algunos, hubo otros que decidieron de manera voluntaria unirse a las patrullas y a los comisionados militares, y que fueron participes de la violencia contra miembros de su propia comunidad pues encontraron aquí un recurso de poder que en su condición de indígenas, en un país racista como Guatemala, les había sido negado siempre. La memoria local posibilita además tejer las historias de más larga duración, ubicar que los pueblos tienen una raíz de lucha y resistencia que viene desde hace cientos de años y se va reconfigurando en distintos momentos de la historia; éstas han sido historias silenciadas que no aparecen en el recuento de la historia nacional.

El vislumbrar estas otras historias nos mueve inmediatamente de la concepción victimizante y sufriente, se escribe entonces una historia distinta donde los pueblos indígenas no son los pobrecitos, los menores de edad que han sido siempre tutelados, así concebidos colonialmente, y que no pueden por tanto hablar con voz propia, sino que necesitan la intermediación de otro. $\mathrm{Al}$ afirmar su identidad como sujetos se les regresa también una responsabilidad histórica de haber participado en la construcción social con sus apuestas emancipadoras y también con su carácter opresivo, y desde ese lugar de actores pueden entonces tejerse apuestas de futuro.

De igual manera ocurre con el vacío historiográfico que ha existido en torno a las mujeres, negándoles que pueden tener un papel protagónico y colocándolas siempre en un segundo plano. En los trabajos que revisamos pudimos ver la importancia que tuvo poner a las mujeres en el centro de los 
procesos de memoria, romper el silencio para poder hablar de lo que a ellas les había pasado y no a los otros. El comenzar a hablar de lo vivido, reconocer el dolor y ponerlo en colectivo fue lo que permitió a estas mujeres romper con la culpa y la victimización, dejar de esperar que sean otras y otros los que resuelvan lo que está dentro de ellas y comenzar a hacerse cargo de su propio bienestar. A través del trabajo colectivo las mujeres pudieron dimensionar la violación sexual como una estrategia de guerra, devolver la culpabilidad al agresor y dar un giro en el discurso dejando de colocarse como las agredidas, las víctimas, comenzando a posicionarse como sobrevivientes que lograron defender su vida ante un atroz contexto. Son entonces mujeres fuertes, que tuvieron la potencia para mantenerse con vida y no mujeres débiles como se habían sentido siempre, al reconocerles esa fuerza que vive en ellas pueden entonces posicionarse en el presente y en el futuro con los cambios y transformaciones a las que aspiran.

Finalmente pudimos ver cómo la experiencia de los hijos aporta a la ruptura de la victimización en tanto se rescata el ser luchador activo, se reivindican las causas de esta lucha entendiendo su raíz estructural. Otro gran aporte de los procesos emprendidos por los familiares es la exigencia de justicia, que si bien pone el acento en las acciones que han cometido los soldados y el gobierno contra las poblaciones y los luchadores sociales lo hace bajo la premisa de que ninguna acción de este tipo justifica la violencia tan atroz ejercida, la tortura ni el asesinato, puesto que son seres humanos. Con lo anterior, hay un querer resignificar a los actores a través del sentido de la dignidad.

Podemos afirmar, entonces, que la historia y la memoria son, ambas, territorios de disputa en los que vale la pena hacer una clara apuesta política para desmontar la victimización y asumirnos como sujetos transformadores. 


\section{Bibliografía citada}

Asociación de Veteranos Militares de Guatemala, 1998, Guatemala, testimonio de una agresión, Avemilgua, Ciudad de Guatemala.

Bataillon, Gilles, 2008, Génesis de las guerras intestinas en América Central (1960-1983), Fondo de Cultura Económica, México, D.F.

Bert, Janssens (coordinador), 2003, OjK'aslik. Estamos vivos: Recuperación de la memoria histórica de Rabinal (1944-1996), Museo Comunitario Rabinal Achí, Rabinal, Baja Verapaz, Guatemala.

Comisión para el Esclarecimiento Histórico (CEH), 1999, Guatemala Memoria del silencio. Guatemala, Oficina de Servicios para Proyectos de las Naciones Unidas, Ciudad de Guatemala.

De León, Quimy y Nelton Rivera, 2014, “Todo está cargado en la memoria: un museo para no olvidar”, Prensa Comunitaria, 20 de mayo de 2014, en https://comunitariapress. wordpress.com/2014/05/20/todo-estacargado-en-la-memoria-un-museo-para-no-olvidar/

Doyle, Kate, 2011, "Restos de dos víctimas del diario militar de Guatemala encontrados en una fosa común", National Security Archive Electronic Briefing Book, núm. 363, 22 de noviembre de 2011, en http:// nsarchive.gwu.edu/NSAEBB/NSAEBB363/index2.htm

Dussel, Enrique, 1998, Ética de la liberación en la edad de la globalización y de la exclusión, Editorial Trotta, España.

Falla, Ricardo, 1992, Masacres en la selva. Ixcán, Guatemala (1975-1982), Editorial Universitaria, Ciudad de Guatemala.

Fulchiron, Amandine, 2006, "La denuncia de la violencia sexual cometida durante la guerra en Guatemala: ¿un camino hacia la negociación de un nuevo contrato sexual?", Congreso Latin American Studies Association, Puerto Rico.

Fulchiron, Amandine, Olga Alicia Paz y Angélica López, 2009, Tejidos que lleva el alma. Memoria de las mujeres mayas sobrevivientes de la violación sexual durante el conflicto armado, ECAP/UNAMG/F\&G editores, Ciudad de Guatemala.

Fundación Myrna Mack, 2003, El Diario Militar: Rastros de la verdad, Guatemala.

Grandin, Greg, 2007, “Las instrucciones de las grandes catástrofes: Comisiones por la verdad, la historia nacional y la formación del Estado en 
Argentina, Chile y Guatemala”, (en línea) Sociohistórica: Cuadernos del CISH, núm. 21-22, disponible en http://www.sociohistorica. fahce.unlp.edu.ar/ article/viewFile/SHn21-22a09/1682

Hernández Alarcón, Rosalinda, Andrea Carrillo Samayoa et al., 2008, Memorias rebeldes contra el olvido: PaasantizilaTxumb'al Ti' Sotxeb 'alK'u'l, Avancso/La Cuerda/Plataforma Agraria/Magna Terra Editores, Ciudad de Guatemala.

Horkheimer, Max y Theodor W. Adorno, 1994, Dialéctica de la ilustración, Editorial Trotta, Madrid, España.

Hurtado Paz y Paz, Margarita, 2009, Organización y lucha rural, campesina e indigena: Huehuetenango, Guatemala, 1981, FLACSO, Ciudad de Guatemala.

Iniciativa para la Reconstrucción y Recuperación de la Memoria Histórica (IRRMH), 2012, Nuestro entendimiento común sobre la historia de nuestras tierras, nuestros pueblos y nuestras resistencias, Coordinación por los Derechos de los Pueblos Indígenas, Ciudad de Guatemala.

Le Bot, Yvon, 1995, La guerra en tierras mayas: Comunidad, violencia y modernidad en Guatemala (1970-1992), Fondo de Cultura Económica, México, D.F.

Macías, Julio César, 1998, Mi camino: La guerrilla. La apasionante autobiografía del legendario combatiente centroamericano César Montes, Editorial Planeta, México, D.F.

Mendizábal Saravia, Helvi (editora), 2005. Desafíos y potencialidades de la historia local de Guatemala, Memoria del Taller, Avancso, Ciudad de Guatemala.

Meoño, Gustavo, 2012, "El perdón y el olvido por decreto no existen. Y lo que es peor: tampoco funcionan”, El periódico [Guatemala], 6 de diciembre de 2012, p. 26.

Mérida González, Mario Alfredo, 2000, Testigo de Conciencia. Periodismo de Opinión Documentado, s/e, Ciudad de Guatemala.

Monzón, Ana Silvia, 2005, "Entre silencios y olvidos emergen las memorias de las mujeres guatemaltecas", en Mercie Mersky y Simone Remijnse (coordinadoras), Memoria e historia. Seminario internacional en homenaje a Myrna Mark, Avancso, Ciudad de Guatemala. 
Oficina de Derechos Humanos del Arzobispado de Guatemala, 1998, Guatemala Nunca Más, ODHAG, Ciudad de Guatemala.

Palma Lau, Pedro Pablo, 2010, Sierra Madre: Pasajes y perfiles de la guerra revolucionaria, F\&G editores, Ciudad de Guatemala.

Payeras, Mario, 1981, Los días en la selva, Casa de Las América, Cuba.

Payeras, Mario, 1987, El trueno en la ciudad. Episodios de la lucha urbana armada de 1981 en Guatemala, Juan Pablos Editor, México, D.F.

Rouquié, Alain, 1994, Guerras y paz en América Central, Fondo de Cultura Económica, México, D.F.

Sabino, Carlos, 2008, Guatemala, la historia silenciada (1944-1989), Tomo II: El dominó que no cayó, Fondo de Cultura Económica, México, D.F.

Santa Cruz Mendoza, Santiago, 2004, Insurgentes. Guatemala, la paz arrancada, LOM ediciones, Chile.

Soriano Hernández, Silvia, 2004, Mujeres y guerra en Guatemala y Chiapas, Tesis para obtener el grado de doctora en estudios latinoamericanos, posgrado en estudios latinoamericanos, Universidad Nacional Autónoma de México, México.

Soriano Hernández, Silvia, 2006, Mujeres y guerra en Guatemala y Chiapas, UNAM/Centro Coordinadory Difusor de Estudios Latinoamericanos, México, D.F.

Stoll, David, 1999, Entre dos fuegos en los pueblos ixiles de Guatemala, Ediciones Abya-Yala, Quito, Ecuador.

Taracena Arriola, Arturo, 2007, "La experiencia de un historiador en la Comisión de Esclarecimiento Histórico de Guatemala", en Anne Pérotin-Dumon (dir.), Historizar el pasado vivo en América Latina, en http://etica.uahurtado.cl/historizarelpasadovivo/es_contenido.php

Torres Rivas, Edelberto, 2007, "Prólogo", en Roddy Brett, Una guerra sin batallas: Del odio, la violencia y el miedo en el Ixcán y el Ixil, 19721983, F\&G editores, Guatemala.

Vela Castañeda, Manolo E., 2011, "Notas teóricas y metodológicas", en Guatemala, la infinita historia de las resistencias, Secretaría de la Paz de la Presidencia de la República/Magna Terra Editores, Ciudad de Guatemala. 


\section{Entrevistas}

Samuel Villatoro, Ciudad de Guatemala, 6 de noviembre de 2012.

Flor de María Calderón, Ciudad de Guatemala, 20 de enero de 2013.

Javier Gurriarán, Ciudad de Guatemala, 19 de noviembre de 2013. 